\title{
Tackling the perils of unawareness: the cluster headache case
}

\author{
Giorgio Lambru', Anna P. Andreou ${ }^{1,2}$, Elena Ruiz de la Torre ${ }^{3}$ and Paolo Martelletti ${ }^{4,5,6^{*}}$ (D)
}

\section{Cluster headache unawareness}

The $21^{\text {st }}$ of March 2017 has marked a remarkable collective effort to raise public awareness of cluster headache $(\mathrm{CH})$. This campaign has inspired an explosion of initiatives aimed to raise awareness of this devastating, yet neglected condition to the level of other neurological disorders. The collaboration between several stakeholders, namely the European Headache Federation [1], patient support groups such as the Organisation for the Understanding of Cluster Headache $(\mathrm{OUCH})$ in the United Kingdom (UK) [2], the European Headache Alliance (EHA), the European Federation of Neurological Associations [3], the European Brain Council [4], many headache centres led by the Guy's and St Thomas' Headache Centre (London, UK) and the La Sapienza University Headache Centre at St Andrea Hospital, (Rome, Italy), Members of Parliament of the European Union and the UK, publishers [5] and the media [6], has provided a unique platform to discuss strategies to tackle the unmet need in $\mathrm{CH}$. These bodies are all in agreement that the emphasis should be on: increasing awareness of $\mathrm{CH}$; advancing the understanding and management of the condition; and ensuring standardised, high-quality care across Europe and the UK.

\section{Cluster headache is still lurking in the shadows}

Although the clinical phenotype of cluster headache is typical and unmistakable, in practice, misdiagnosis is unfortunately common. Cluster headache is a quasi-rare primary headache disorder characterised by unilateral, sharp, stabbing pain rapidly reaching an excruciating intensity. The pain is typically felt around the orbit and temporal area and usually lasts between 15 and $180 \mathrm{~min}$. The attacks are frequently described as feeling like a "red hot poker in the eye". The pain is accompanied by at least one of the cranial autonomic symptoms [7]. Up

\footnotetext{
* Correspondence: paolo.martelletti@uniroma1.it

${ }^{4}$ Regional Referral Headache Centre, Sant'Andrea Hospital, Rome, Italy

${ }^{5}$ Department of Clinical and Molecular Medicine, Sapienza University of

Rome, Rome, Italy

Full list of author information is available at the end of the article
}

to $93 \%$ of patients describe a sense of restlessness and agitation during the attacks [8]. The frequency of attacks ranges from once every other day up to eight episodes per day and, in episodic $\mathrm{CH}$, are grouped in bouts lasting from a few weeks to a few months. They follow a striking tendency to circadian periodicity with a preponderance of attacks during the sleep phase. Furthermore, they may demonstrate a circannual periodicity, with active bouts peaking during seasonal changes, particularly the solstices and equinoxes (episodic $\mathrm{CH}$ ). Unfortunately, approximately $10-20 \%$ of patients may develop the chronic form of $\mathrm{CH}$, without any remission period of more than a month (chronic $\mathrm{CH}$ ). Some people evolve from the episodic to the chronic form or vice-versa and some enter prolonged remission periods. However, the factors contributing to these pattern transitions are yet to be explained.

Despite its peculiar phenotype, only a small proportion of these patients are correctly diagnosed and many still face an average delay of 5.3 years before the correct diagnosis is made. Consequently, many sufferers may never receive the correct diagnosis and, of those who do, a significant minority still do not receive appropriate treatments [9]. Part of the problem is the lack of training in the medical schools, at the level of general practitioners and even higher, in the neurology specialty. There is little research assessing the burden of $\mathrm{CH}$ so it is difficult to express the impact that these inadequacies has on those with the condition, and the wider society. Large epidemiological projects are required to further clarify the disability associated with both the episodic and chronic forms of the condition and thus help $\mathrm{CH}$ gain the deserved recognition amongst other neurological disorders with a similar prevalence, such as multiple sclerosis [10]. The Global Burden of Diseases studies, which are acknowledged internationally as comprehensive reports in health metrics, morbidity and mortality, have yet to present any data on the burden and disability of $\mathrm{CH}$ [11].

The observance of the $\mathrm{CH}$ awareness day during the spring equinox highlights one of the many stereotypical 
features of this condition, which was known for over 350 years within the neuroscience community. The seasonal periodicity of $\mathrm{CH}$ has given the opportunity to disentangle the complex biological mechanisms of this fascinating brain disorder by focusing on neuronal structures that can produce stereotypical episodes of extreme head pain following a striking circadian and circannual periodicity. Indeed functional, structural and neurohormonal studies have confirmed the importance of the region that modulates fundamental circadian rhythms in mammals, namely the suprachiasmatic nucleus of the hypothalamus [12]. However, the factors that regulate the periodic derangements of the chronobiological activities relevant in $\mathrm{CH}$ is still far from understood. Resting state functional magnetic resonance studies have tried to shed light on networks relevant in $\mathrm{CH}$ by exploring functional connectivity changes in and outside $\mathrm{CH}$ bouts $[13,14]$. Furthermore, several studies have tried to find a genetic signature that may increase the risk of developing $\mathrm{CH}$, looking at pain processing, neuro-inflammatory and vascular markers, trigger factors, ion channels and clock genes, with little success $[15,16]$. Recently, polymorphisms of the hypocretin receptor-2 gene (HCRTR2) have been associated with $\mathrm{CH}$ [17]. Together with the reduced cerebrospinal fluid levels of hypocretin-1 in $\mathrm{CH}$ patients [18], these data pointed towards the importance of an imbalance of the hypocretin system activity in $\mathrm{CH}$ and its possible role in modulating trigemino-vascular processes [19].

Lack of research funding has only allowed sparse studies aiming to unravel the pathophysiology of $\mathrm{CH}$ or the mechanisms of action of drugs that abort or prevent $\mathrm{CH}$ attacks. Part of the effort in raising awareness for this devastating disease includes the demand for specific funding streams in $\mathrm{CH}$ research. Further understanding of the pathophysiology of $\mathrm{CH}$ may stimulate the development of novel treatments targeting specific pathways for this disease. Indeed, for far too long the arsenal of treatments for $\mathrm{CH}$ has been limited to triptans and oxygen amongst abortive treatments, and verapamil, corticosteroids and lithium for $\mathrm{CH}$ prevention.

\section{Brightening the "cluster headache days"}

Based on the promising data coming from studies using monoclonal antibodies against Calcitonin Gene-Related Peptide (CGRP) for migraine prevention, there are now randomised controlled phase III trials using these antibodies specifically for episodic and chronic cluster headache $[20,21]$. Targeting CGRP in $\mathrm{CH}$ may offer new, more specific and potentially better-tolerated treatments. Advances in the neuromodulation field have also benefited people with the chronic subtype of $\mathrm{CH}$ who may have become refractory to the limited arsenal of pharmacological treatments available.
Over the years, the application of neurostimulation therapies has progressed from very invasive approaches, such as deep brain stimulation, to less invasive ones, namely occipital nerve stimulation [22] with promising outcomes in challenging-to-treat group of patients. Recently, the stimulation of the sphenopalatine ganglion (SPG), using a wireless microstimulator able to deliver on demand electrical therapy, has been shown for the first time to be effective in aborting and preventing $\mathrm{CH}$ attacks [23]. Despite these advances in the treatment of $\mathrm{CH}$, there is an urgent need for policy makers to facilitate the implementation in clinical settings of new evidence-based treatments for chronic $\mathrm{CH}$ to help reduce the devastating burden of this condition [24-26].

In conclusion, the 2017 Cluster Headache Awareness day incorporated joint efforts, directed to the general public, governments, policy makers, healthcare professionals and the media, to emphasise the unmet needs of this underdiagnosed and mistreated condition. For far too long lack of awareness, misperception of its burden and lack of research funding have hindered developments in the understanding of the condition. Challenging these historical issues is our responsibility. Offering a brighter future for patients, our accountability.

\section{Acknowledgments \\ We thank our Headache Specialist Nurse at Guy's and St Thomas' NHS Foundation Trust, Mrs Madeleine Murphy, for her involvement in the cluster headache initiative; we also thank cluster headache patients and their families for their support of this initiative.}

Authors' contributions

All authors drafted, discussed, read and approved the final manuscript.

\section{Authors' information}

Giorgio Lambru is the Clinical Lead of the Headache Centre, Guy's and St Thomas's NHS Foundation Trust.

Anna Andreou is the Director of Headache Research of the Headache Centre, at Guy's and St Thomas's NHS Trust and King's College London. Elena Ruiz de la Torre, is the President of European Headache Alliance. Paolo Martelletti, is the Lead of the Headache Centre at Sant'Andrea Hospital, Sapienza University of Rome, Italy and the President of European Headache Federation.

Competing interests

The authors declare that they have any competing interests.

\section{Publisher's Note}

Springer Nature remains neutral with regard to jurisdictional claims in published maps and institutional affiliations.

\section{Author details}

'Headache Centre, Guy's and St Thomas' NHS Trust, London, UK. 'Headache Research - Wolfson CARD, King's College London, London, UK. ${ }^{3} E u r o p e a n$ Headache Alliance, Brussels, Belgium. ${ }^{4}$ Regional Referral Headache Centre, Sant'Andrea Hospital, Rome, Italy. ${ }^{5}$ Department of Clinical and Molecular Medicine, Sapienza University of Rome, Rome, Italy. ${ }^{6}$ European Headache Federation, London, UK. 
Received: 20 April 2017 Accepted: 21 April 2017

Published online: 27 April 2017

\section{References}

1. http://ehf-org.org/cluster-headache-awareness-day-2017/, accessed 21 March 2017

2. https://ouchuk.org/news/cluster-headache-awareness-day, accessed 21 March 2017

3. http://efna.net/cluster-headache-awareness-day-2017/, accessed 21 March 2017

4. http://www.braincouncileu/activities/news/press-release-cluster-headacheday-event-21st-march/, accessed 21 March 2017

5. http://www.springeropen.com/p/clinicalmedicine-awarenessclusterheadache, accessed 21 March 2017

6. http://blogs.springeropen.com/springeropen/2017/03/21/supporting-clusterheadache-awareness-day-21 st-march-2017/, accessed 21 March 2017

7. Headache Classification Subcommittee of The International Headache Society (2013) The International Classification of Headache Disorders 3rd edition (beta version). Cephalalgia 33(9):629-808

8. Blau J (1993) Behaviour during a cluster headache. Lancet 342:723-725

9. Voiticovschi-losob C, Allena M, De Cillis I, Nappi G, Sjaastad O, Antonaci F (2014) Diagnostic and therapeutic errors in cluster headache: a hospitalbased study. J Headache Pain 15:56

10. Fischera M, Marziniak M, Gralow I, Evers S (2008) The incidence and prevalence of cluster headache: a meta-analysis of population-based studies. Cephalalgia 28:614-618

11. Leonardi M, Steiner TJ, Scher AT, Lipton RB (2005) The global burden of migraine: measuring disability in headache disorders with WHO's Classification of Functioning, Disability and Health (ICF). J Headache Pain 6:429-440

12. Leone M, Bussone G (2009) Pathophysiology of trigeminal autonomic cephalalgias. Lancet Neurol 8:755-764

13. Chiapparini L (2015) Resting state fMRI in cluster headache: which role? Neurol Sci 36(Suppl 1):47-50

14. Yang FC, Yang FC, Chou KH, Fuh JL, Lee PL, Lirng JF, Lin YY, Lin CP, Wang SJ (2015) Altered hypothalamic functional connectivity in cluster headache: a longitudinal resting-state functional MRI study. J Neurol Neurosurg Psychiatry 86:437-445

15. Cainazzo MM, Tiraferri I, Ciccarese M, Martinelli A, Cameli C, Bacchelli E, Zoli M, Pini LA (2015) O015. Evaluation of the genetic polymorphism of the alpha3 (CHRNA3) and alpha5 (CHRNA5) nicotinic receptor subunits, in patients with cluster headache. J Headache Pain 16:A88

16. Sjostrand C (2009) Genetic aspects of cluster headache. Expert Rev Neurother 9:359-368

17. Weller CM, Wilbrink LA, Houwing-Duistermaat JJ, Koelewijn SC, Vijfhuizen LS, Haan J, Ferrari MD, Terwindt GM, van den Maagdenberg AM, de Vries B (2015) Cluster headache and the hypocretin receptor 2 reconsidered: a genetic association study and meta-analysis. Cephalalgia 35:741-747

18. Cevoli S, Pizza F, Grimaldi D, Nicodemo M, Favoni V, Pierangeli G, Valko PO, Baumann CR, Montagna P, Bassetti CL, Cortelli P (2011) Cerebrospinal fluid hypocretin-1 levels during the active period of cluster headache. Cephalalgia 31:973-976

19. Rainero I, De Martino P, Pinessi L (2008) Hypocretins and primary headaches: neurobiology and clinical implications. Expert Rev Neurother 8:409-416

20. US National Library of Medicine (2016) ClinicalTrials.gov https://clinicaltrials. gov/ct2/show/NCT02397473. Accessed 21 Mar 2017.

21. US National Library of Medicine (2016) ClinicalTrials.gov https://Clinicaltrials. gov/ct2/show/NCT02438826. Accessed 21 Mar 2017.

22. Ambrosini A (2007) Occipital nerve stimulation for intractable cluster headache. Lancet 369:1063-1065

23. Jurgens TP, Schoenen J, Rostgaard J, Hillerup S, Láinez MJ, Assaf AT, May A, Jensen RH (2014) Stimulation of the sphenopalatine ganglion in intractable cluster headache: expert consensus on patient selection and standards of care. Cephalalgia 34:1100-1110

24. Martelletti P, Curto M (2016) Headache: Cluster headache treatment - RCTs versus real-world evidence. Nat Rev Neurol 12:557-558

25. Martelletti P, Mitsikostas DD (2015) Cluster headache: a quasi-rare disorder needing a reappraisal. J Headache Pain 16:59

26. Martelletti P (2015) Cluster headache management and beyond. Expert Opin Pharmacother 16:1411-1415

\section{Submit your manuscript to a SpringerOpen ${ }^{\circ}$ journal and benefit from:}

- Convenient online submission

- Rigorous peer review

- Immediate publication on acceptance

- Open access: articles freely available online

- High visibility within the field

- Retaining the copyright to your article

Submit your next manuscript at $\gg$ springeropen.com 